\title{
Vaginal Delivery through Posterior Cervical Tear without Dilatation of Cervical Os
}

\author{
Jayanth Nagendranath Chilkund ${ }^{1}$, Siddhi Shailesh Kore², Kruti Mahendra Mehta ${ }^{3}$
}

${ }^{1}$ Department of Obstetrics and Gynaecology, Pt. MMM Shatabdi Hospital, Govandi, Mumbai, Maharashtra, India. ${ }^{2}$ Department of Obstetrics and Gynaecology, Pt. MMM Shatabdi Hospital, Govandi, Mumbai, Maharashtra, India. ${ }^{3}$ Department of Obstetrics and Gynaecology, Pt. MMM Shatabdi Hospital, Govandi, Mumbai, Maharashtra, India.

\section{PRESENTATION OF CASE}

A 23-year-old primigravida with no previous history of abortions or miscarriages with spontaneous conception and singleton pregnancy was admitted to the labour ward at 40 weeks 5 days of gestation for induction of labour. She had antenatal workup and immunization as per standard antenatal care (ANC) protocol with regular antenatal visits. She had uneventful antenatal period without any high-risk factors (no hypertension, gestational diabetes or anaemia). There was no history of any medical illness and abdomino-pelvic surgical interventions.

On examination, her vital parameters were normal. Uterus full term gestation with fetus in longitudinal lie and cephalic position. Liquor appeared adequate and fetal heart sounds were heard at normal rate in the left lower quadrant. Ultrasonography done prior to admission showed normal findings with estimated baby weight of $2.8 \mathrm{Kg}$ and normal Doppler flows and adequate liquor.

Speculum and digital examination was done on admission which revealed the following- No cervical or vaginal injuries or lesions. A long tubular cervix (approx. 2 $\mathrm{cm}-2.5 \mathrm{~cm}$ ), midpositioned admitting just tip of a finger. No bleeding or leaking with a BISHOPS score of 4.(1)

Non stress test trace was done which showed a reactive state.

After counseling and with informed written consent (appendix C, good clinical practice guidelines, FOGSI-ICOG 2018),(1) induction of labour was done with Cerviprime gel (dinoprostone $0.5 \mathrm{mg}$ ) for postdatism under all aseptic precautions to promote cervical ripening and subsequent onset of labour.

There were no uterine activity and per vaginal examination done after 6 hours showed that findings remained same as before induction. Thus, a repeat well informed written consent was taken for reinstallation of Cerviprime gel.(1)

Patient started getting regular uterine contractions after 30 mins of instillation of gel. The progress of labour was monitored. Fetal heart was monitored by Electronic fetal heart monitor. As patient was getting good strong uterine contractions, a decision for per vaginal examination was taken and it was done after 1 hour which showed ballooning of posterior cervix with good descent of head and a non-dilating external cervical os. Then after 15 mins, suddenly, crowning of head was noticed, and the baby was delivered with episiotomy. Placenta and membranes were removed entirely and profuse active bleeding was noted. Baby weighed at $2.7 \mathrm{Kgs}$.

\author{
Corresponding Author: \\ Jayanth Chilkund, \\ 102, Udhyan CHS, \\ Plot No. 63, Sector 21, \\ Nerul, Navi Mumbai-400706, \\ Maharashtra, India. \\ E-mail: jayanthchilkund@gmail.com
}

DOI: $10.14260 / \mathrm{jemds} / 2020 / 366$

Financial or Other Competing Interests: None.

How to Cite This Article:

Chilkund JN, Kore SS, Mehta KM. Vaginal delivery through posterior cervical tear without dilatation of cervical os. J. Evolution Med. Dent. Sci. 2020;9(21):16691671, DOI: $10.14260 /$ jemds/2020/366

Submission 21-03-2020,

Peer Review 04-05-2020,

Acceptance 11-05-2020,

Published 25-05-2020.

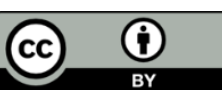


On per speculum examination, the cervical os was closed and a posterior cervical tear of around $4 \mathrm{cms}$ semi lunar on cervix from 3 to $90^{\prime}$ clock position was found. Figure 1 represents it schematically. The cervical tear was sutured with atraumatic Vicryl no 2.0. Picture 2 shows the sutured cervical tear. PPH was controlled as per standard protocol. Two units of PRBC (packed Red blood cells) and crystalloid infusion were administered for maintaining hemodynamic stability.

Patient had uneventful recovery. After 24 hours ultrasonography scan showed a collection of haemorrhagic blood clot of $6 \mathrm{cms} \times 4 \mathrm{cms}$ in the cervix. This was managed conservatively.(2) She was discharged on $5^{\text {th }}$ day of delivery and followed up after 6 weeks. A speculum examination and digital examination revealed a normal size uterus and a completely healed cervix.

Cervical injuries occur during vaginal delivery due to various reasons. The commonest being Operative Vaginal delivery (vacuum assisted or forceps application), precipitous labour, any surgical interventions on the cervix like cervical encirclage. They can also occur with cervical neoplasm and cervical lesions. Induction of labour increases the possibility of cervical damage. Cervical injuries contribute to the morbidities associated with injuries during vaginal delivery. This is a report of a case of vaginal delivery through a cervical tear without complete cervical dilatation.

However a cervical tear large enough to mimic a full cervical dilatation and allowing the passage of the fetus resulting in vaginal delivery is a rarity. Induction of labour is associated with three-fold increase in cervical tears. Softening of cervix with ballooning and a rigid external os should raise a suspicion of an imminent cervical tear or rupture. Although conventional guidelines for good clinical practice do suggest repeat instillation after 6-8 hours, it is probably prudent to repeat the next instillation after 24 hours.

\section{CLINICAL DIAGNOSIS}

Vaginal delivery through a posterior cervical tear after induction of labour with Cerviprime gel in a primigravida with post-dated pregnancy.

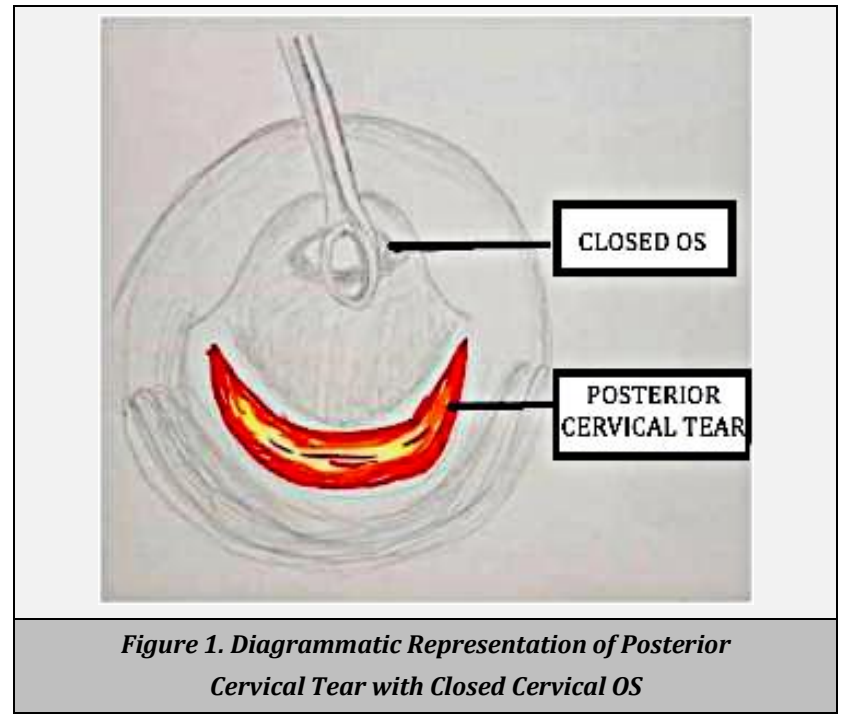

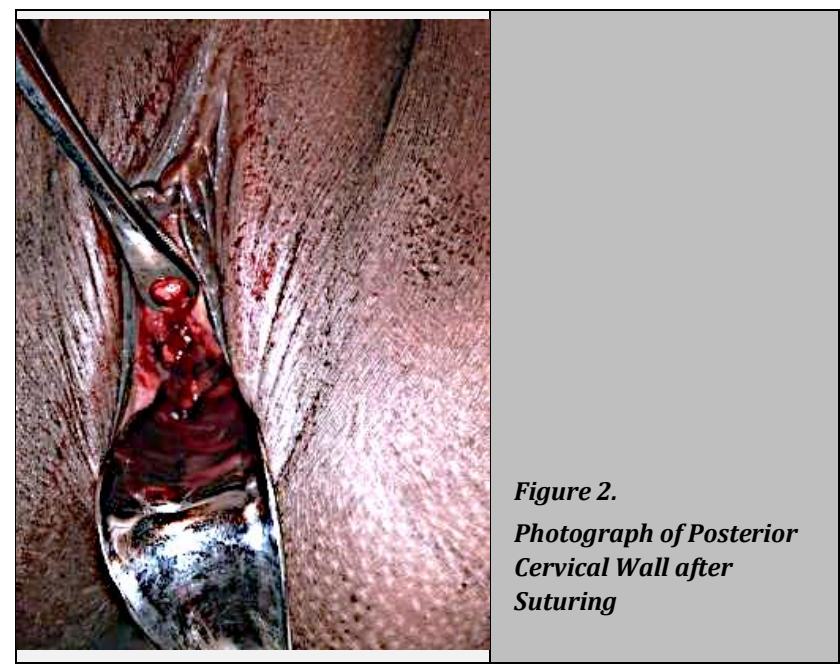

\section{DISCUSSION MANAGEMENT}

There are several causes of cervical tear such as operative vaginal delivery with forceps or vacuum cup, abnormal structure of cervix due to scarring because of previous surgical interventions such as cervical encircalage, rapid delivery of head in breech presentation, manual dilatation of cervix, hyper stimulation of uterus, and obstructed labour. However, a large tear that mimics a full dilatation of cervix and leads to delivery of the fetus through posterior tear is a rare incidence. The incidence of cervical laceration in normal delivery is $0.2 \%$ and increases by 11 -fold with history of cervical encircalage and increases by 3-fold with use of forceps or vacuum cup. ${ }^{\text {(3) }}$ (AJOG MAY 2007). Cervical circlage was found to be associated with an 11.5-fold increase, and induction of labour was associated with a 3.1-fold increase in the rate of cervical lacerations.(3) Cervical tear occurs in more than a half of normal vaginal deliveries which rarely requires repair if not bleeding and measures less than $0.5 \mathrm{~cm} .{ }^{(4)}$

Even operative vaginal deliveries which include forceps delivery and vaccum delivery have higher risk of soft tissue injury.(5) Operative vaginal delivery is conducted for maternal as well as fetal conditions when there is need to cut short second stage of labour. A study conducted in northwest Ethiopia found $12.1 \%$ proportion of maternal complications related to instrumental delivery. Out of which $1.5 \%$ was cervical tears. However cervical tear with vacuum assisted delivery was only $0.5 \%$ as compare to forceps.(6)

Now a days cervical encircalge is a very common procedure performed with increase in availability of $3 \mathrm{D}$ scan facilities, pregnancies following in-vitro fertilization techniques, and pregnancy following treatment for repeated pregnancy losses. One of the complications with cervical encircalage is cervical lacerations and tear.(7) Harger JH in his study of comparison of success and morbidity in cervical cerclage procedure quotes that around $11 \%$ presents with cervical laceration using Shirodkar method as compared to $14 \%$ with McDonald method, which is quite significant number.(8),(9)

In another study about 11.5 -fold increase in cervical laceration was found after cervical encirclage.(3) Any kind of 
cervical intervention can be a high risk to cause cervical tear eg. loop electro surgical excision.(10)

The rate of induction of labour has increased probably due to availability of induction agents,over conscious doctors,pressure built from patients, better health care facilities and surgical facilties.(7)

Induction of labour is indicated in premature rupture of membranes, post-term pregnancy, preterm prelabour rupture of membranes (PPROM),suspected macrosomia, gestational diabetes mellitus, cardiac disease, fetal anomalies, systemic lupus erythematosis, oligohydramnios, alloimmunization, rhesus disease, intrahepatic cholestasis of pregnancy (IHCP), and intrauterine growth restriction (IUGR).(1)

Methods for induction include: prostaglandin medication in form of oral or vaginal prostaglandins E2 (PGE2) or misoprostol, mechanical methods (including Foley catheters and double-balloon catheters) and oxytocin.(1)

In this patient cerviprime gel (PGE2) was used as agent for induction of labour with indication of post datism. It was introduced intracervically under all aseptic precaution.(11) As compare to oral and parentral method of induction using prostaglandin, the side effects are much less in local applications of prostaglandin E2. Also it has shorter induction delivery time and one time dose response that makes it simple in administartion and causes minimal discomfort to the patient.(12)

It was choosen as the method of induction in our case as studies have shown to have favourable outcomes as compare to other methods with significantly low rates of caesarean section. It is safe for both mother and the baby.(12) Vaginal dinoprostone can also decrease the macrophage function resulting in the overgrowth of clostridial organisms and developmental gangrene of gastrointestinal and reproductive tracts which may accentuate the possibilities of cervical tear.(13)

With the use of Misoprostol, there is evidence to show it as a cause of bucket handle cervical tear after induction of labour. If there is good uterine contraction but no cervical ripening then it is a good option to withhold further doses to avoid cervical injuries.(2)

In this present case, induction of labour was done with dinoprost gel which is PGE2 gel and same was repeated after 6 hours. It is possible that with onset of good uterine activity and softening of lower segment and cervical canal, a spontaneous tear occurred in posterior cervix with external os remaining undilated and this was mistaken as full dilatation at crowning and normal vaginal delivery ensued. It was after the delivery of baby and placenta, a huge rent in posterior cervix was noted.

\section{CONCLUSIONS}

Softening of cervix with ballooning and a rigid external os should raise a suspicion of an imminent cervical tear or rupture. A thorough evaluation before a repeat instillation should be done. Although conventional guidelines for good clinical practice do suggest repeat instillation after 6-8 hours, it is probably prudent to repeat the next instillation after 24 hours.

\section{REFERENCES}

[1] ShanthaKumari S, Malhotra J. Good Clinical Practice Recommendations FOGSI-ICOG 2018. Induction of Labour: Good Clinical Practice Recommendations, Chairperson, ICOG President, FOGSI. 2018.

[2] Singhal SR, Singhal SK. Bucket-handle tear of posterior uterine cervical lip in a second-trimester unscarred uterus after use of misoprostol: a first report of two cases. S Afr J Obstet \& Gynaecol 2017;23(2):71-2.

[3] Parikh R, Brotzman S, Anasti JN. Cervical lacerations: some surprising facts. Am J Obstet Gynecol 2007;196(5):e17-8.

[4] Cunningham FG, Gant NF, Leveno KJ. Obstetrical haemorrhage. New York: McGraw-Hill Publication 2001: p. 644-5.

[5] Kabiru WN, Jamieson D, Graves W, et al. Trends in operative vaginal delivery rates and associated maternal complication rates in an inner-city hospital. Am J Obstet Gynecol 2001;184(6):1112-4.

[6] Biru S, Addisu D, Kassa S, et al. Maternal complication related to instrumental delivery at Felege Hiwot Specialized Hospital, Northwest Ethiopia: a retrospective cross-sectional study. BMC Res Notes 2019;12(1):482.

[7] Rayburn WF, Zhang J. Rising rates of labor induction: present concerns and future strategies. Obstet Gynecol 2002;100(1):164-7.

[8] Harger JH. Comparison of success and morbidity in cervical cerclage procedures. Obstet Gynecol 1980;56(5):543-8.

[9] Aarnoudse JG, Huisjes HJ. Complications of cerclage. Acta Obstet Gynecol Scand 1979;58(3):255-7.

[10] Viola YTC, Wai-Lam L, Wing-Cheong L. Delivery through a cervical tear in a patient with a history of loop electrosurgical excision procedure and intact cervical Os. Hong Kong J Gynaecol Obstet Midwifery 2012;12(1):86-8.

[11] Bashutheen NS, Sharon M. A study of intracervical PGE2 gel for cervical ripening and induction of labour. Int Contemp Med Res Obstetrics and Gynaecology 2018;5(3):C4-C7.

[12] Bhattacharyya TK, Shandil MS. Comparison of intracervical prostaglandin E2 and intravenous oxytocin in induction of labour. Med J Armed Forces India 1998;54(3):225-8.

[13] Dasari P, Sagili H, Udupi G. Unusual complication of vaginal delivery: Is misoprostal the cause? BMJ Case Rep 2012;2012. pii: bcr2012007005. 